\title{
PENDAMPINGAN PENGELOLAAN TEMPAT WISATA TAMAN HUTAN RAYA SULTAN ADAM (MANDIANGIN) GUNA MENINGKATKAN JUMLAH WISATAWAN
}

\author{
Rahimi Fitri ${ }^{l}$, Subandi ${ }^{2}$, Arifin Noor Asyikin ${ }^{3}$, Agus Setiyo Budi $N^{4}$ \\ Politeknik Negeri Banjarmasin ${ }^{1,2,3,4}$ \\ rahimi_fitri@poliban.ac.id ${ }^{1}$ \\ subandi@poliban.ac.id ${ }^{2}$ \\ arifin@poliban.ac.id ${ }^{3}$ \\ agus_sbn@poliban.ac.id ${ }^{4}$
}

\begin{abstract}
Tourism Object of the Great Forest Park (tahura) Sultan Adam (Mandiangin) is a large forest park located in two different districts, namely the banjar district and the sea land district in the province of Kalimantan. Tahura has tremendous natural tourism potential such as the Riam Kanan Dam, Pine Island, Bukit Batas Island, Surian Waterfall, Begugur Waterfall ait, Awang Bangkal Campground, Dutch Heritage Site called Dutch Fortress and so on. Governor No. DA.144 / PHT / 1980 dated December 31, 1980 with an area of $+2,000$ hectares. Potential to be a potential source of income for the community or for the surrounding community. At present the visitors of the Sultan Adam are more populated by local residents from the surrounding area, this is due to tourism locations that have not been exposed globally and internationally. At present the South Kalimantan provincial government has a website that publishes news related to tahura but the news that is disclosed is not up-to-date. Based on this context, it is necessary to ignore the community in the form of accompanying the forest park manager using the use and management training website. You can update the news on the web and visitors / tourists are facilitated in finding information about the Sultan Adam Forest Park tour in South Kalimantan Province, with this, their hopes, the number of visitors to objects that can increase and have a positive impact on the surrounding community and district government.
\end{abstract}

Keywords: mentoring, Sultan Adam Forest Park, tourist attraction, website

\begin{abstract}
ABSTRAK
Objek Wisata Taman Hutan Raya (tahura) Sultan Adam (Mandiangin) merupakan taman hutan raya yang berada di dua kabupaten yang berbeda yaitu kabupaten banjar dan kabupaten tanah laut di provinsi kalimantan. Tahura memiliki potensi wisata alam yang luar biasa seperti waduk riam kanan, pulau pinus, pulau bukit batas, Air terjun Surian, ait terjun begugur, bumi perkemahan awang bangkal, situs peninggalan belanda yang bernama benteng belanda serta kawasan ini merupakan kawasan hutan pendidikan UNLAM berdasarkan SK Gubernur No. DA.144/PHT/1980 tanggal 31 desember 1980 dengan luas +2.000 hektar. Potensi pariwisata di tahura merupakan sumber pendapatan yang potensial bagi pemerintah kabupaten maupun bagi masyarakat sekitar. Saat ini pengunjung tahura sultan adam lebih banyak didominasi oleh wisatawan lokal yang berasal dari wilayah sekitar, hal ini dikarenakan lokasi wisata tahura belum terekspose secara nasional maupun internasional. Saat ini pemerintah provinsi kalimantan selatan telah memiliki website yang mempublikasikan berita terkait tahura akan tetapi berita yang disajikan tidak terkini (up to date) sehingga masyarakat yang akan mencari informasi
\end{abstract}


terbaru harus membuka berbagai website yang memuat informasi tentang tahura sultan adam. Berdasarkan permasalahan tersebut maka perlu diadakan pengabdian kepada masyarakat berupa penendampingan pengelolaan taman hutan raya dengan mengadakan pelatihan penggunaan dan pengelolaan website sehingga pengelola dapat selalu memperbaharui berita yang ada didalam web dan pengunjung/ wisatawan dimudahkan dalam mencari informasi tentang wisata Taman Hutan Raya Sultan adam Provinsi Kalimantan selatan, dengan ini harapannya jumlah pengunjung objek wisata tahura menjadi meningkat dan berdampak positif bagi pendapatan warga sekitar dan pemerintah kabupaten setempat

Kata Kunci: objek wisata, pendampingan, Taman Hutan Raya Sultan Adam, website,

\section{PENDAHULUAN}

Objek Wisata Taman Hutan Raya (tahura) Sultan Adam (Mandiangin) merupakan taman hutan raya yang dikelola oleh dinas kehutanan provinsi kalimantan selatan dan berada di dua kabupaten yang berbeda yaitu kabupaten banjar dan kabupaten tanah laut, Nama Tahura ini diambil dari nama Sultan Adam Al-Watsiq Billah bin Sultan Sulaiman Saidullah II yang merupakan Sultan Banjar yang memerintah dari tahun 1825 hingga 1857.

Tahura memiliki potensi wisata alam yang luar biasa seperti waduk riam kanan, pulau pinus, pulau bukit batas, Air terjun Surian, ait terjun begugur, bumi perkemahan awang bangkal, situs peninggalan belanda yang bernama benteng belanda serta kawasan ini merupakan kawasan hutan pendidikan UNLAM berdasarkan SK Gubernur No. DA.144/PHT/1980 tanggal 31 desember 1980 dengan luas +2.000 hektar. Selain petensi wisata tersebut tahura juga memiliki fasilitas pendukung seperti rumah makan, arena bermain, kawasan berkemah, pos keamanan, dan MCK (bappelitbangkabbanjar, 2016).

Objek wisata tahura memiliki potensi untuk dapat menarik banyak pengunjung, hal ini ditunjukkan dari banyaknya tempat yang dapat dikunjungi ketika wisatawan datang ke tahura, hal ini tentu saja dapat sumber pendapatan yang potensial bagi pemerintah kabupaten maupun bagi masyarakat sekitar.

Untuk dapat menarik kunjungan wisatawan pemerintah perlu mempunyai strategi pemasaran yang sesuai untuk dapat mengembangkan kepariwisataan terutama dalam strategi media promosi (Jannah, Sugandi, \& Althalets, 2018).

Promosi objek wisata merupakan suatu kegiatan yang memberitakan atau memberitahukan suatu objek wisata kepada calon wisatawan yang akan dijadikan target pasar, kegiatan ini sebaiknya dilaksanakan secara terus menerus melalui berbagai media yang dianggap efektif dan dapat menjangkau pasar, baik media cetak maupun media elektronik seperti televisi, radio maupun menggunakan media internet (Ch. Wolah, 2016).

Perkembangan teknologi saat ini mendukung kegiatan promosi objek wisata menggunakan media internet, kegiatan ini dirasa sangat efektif untuk menarik minat wisatawan untuk dapat mengunjungi objek wisata tahura.

Saat ini terdapat beberapa website yang didalamnya mengulas tentang objek wisata taman hutan raya sultan adam, website tersebut dikelola oleh dinas kehutanan provinsi kalimantan selatan dan yang dikelola oleh bappelitbang 
bappeda kabupaten banjar, dimana website ini sudah tidak diperbaharui sejak mei 2017.

\section{METODE KEGIATAN}

Berdasarkan latar belakang yang telah dibahas sebelumnya maka permasalahan yang terjadi di tempat mitra dapat diatasi dengan pelatihan pengelolaan website dan media sosial lainnya sehingga masyarakat dapat melihat dan membaca informasi-informasi terkini dari objek wisata Tahura Sultan Adam, hal ini tentu saja akan berdampak positif pada peningkatan jumlah kunjungan wisatawan yang tak hanya wisatawan domestik tetapi juga wisatawan mancanegara. Peningkatan kunjungan wisatawan diharapkan memberikan dampak finansial bagi pengelola Tahura Sultan Adam dan bagi penduduk sekitar objek wisata

Metode pelaksanaan dalam kegiatan pengabdian kepada masyarakat skema pemberdayaan Masyarakat adalah dalam bentuk :

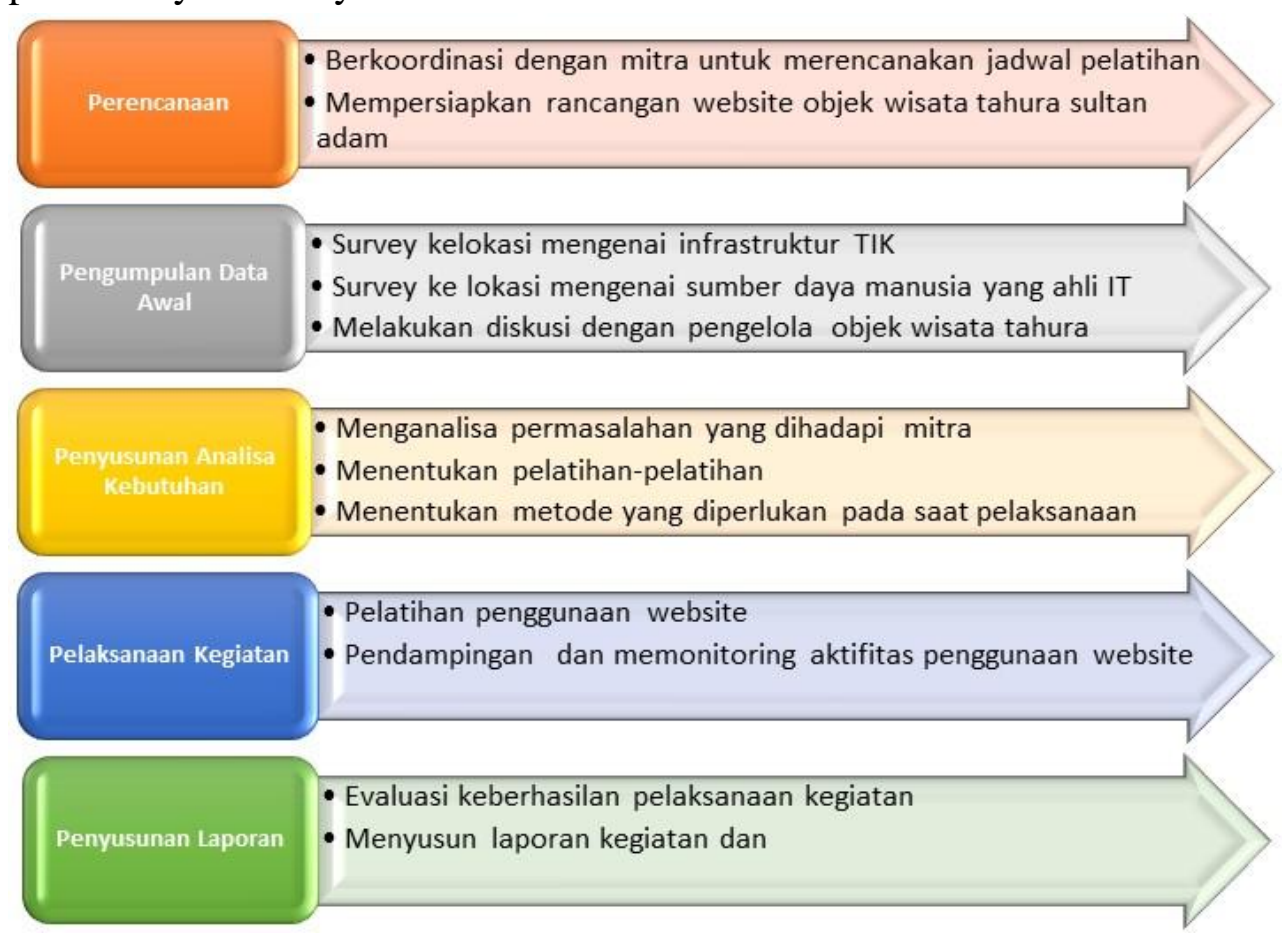

Gambar 1. Metode Pelaksanaan

\section{HASIL DAN PEMBAHASAN}

Berdasarkan langkah-langkah dalam metode pelaksanaan, berikut ini adalah sebagai berikut.

\section{Hasil Survey}

Survey dilaksanakan pada tanggal 6 September 2018, dan melakukan wawancara dengan kepala bidang pengelolaan hutan dinas kehutanan provinsi kalimantan selatan bapak Agung Hananto dengan hasil wawancara yaitu sebagai berikut. 
- Pengelola taman hutan rakyat memerlukan sebuah sistem yang dapat membantu untuk mengelola penyewaan lokasi perkemahan;

- Pengelola memerlukan sistem untuk bisa menampilkan foto-foto kegiatan yang telah dilaksanakan.

\section{Pelaksanaan Kegiatan pengabdian kepada masyarakat}

Kegiatan pengabdian kepada masyarakat dilaksanakan di kantor pengelola taman hutan rakyat (tahura) Mandiangin yang dilaksanakan pada tanggal 7 september 2018. Materi yang disampaikan pada kegiatan tersebut adalah melatih pegawai Tahura yang bertugas sebagai operator website yaitu bapak Erzanie $F$ untuk dapat menggunakan mengelola dat menggunakan website Tahura. Materi disampaikan oleh Arifin Noor Asyikin, Agus Setiyo Budi Nugroho dan Rahimi Fitri dari prodi Teknik Informatika Jurusan teknik Elektro Politeknik Negeri Banjarmasin.

Dalam kegiatan ini tim pengabdian juga melaksanakan kegiatan pengambilan video dan foto udara menggunakan drone untuk sebagai tambahan informasi terkait lokasi tahura mandiang sehingga diharapkan dapat menarik minat pengunjung taman Hutan Rakyat. Gambar 2 sampai dengan 12 adalah foto pelaksanaan kegiatan pengabdian Kepada Masyarakat di Taman Hutan Rakyat Mandiangin.

Gambar 2 berikut ini adalah kegiatan dimana kepala bagian pengelola hutan dinas kehutanan bapak Agung Hananto sedang menjelaskan kondisi kegiatan pengelolaan Tahura Mandiangin.

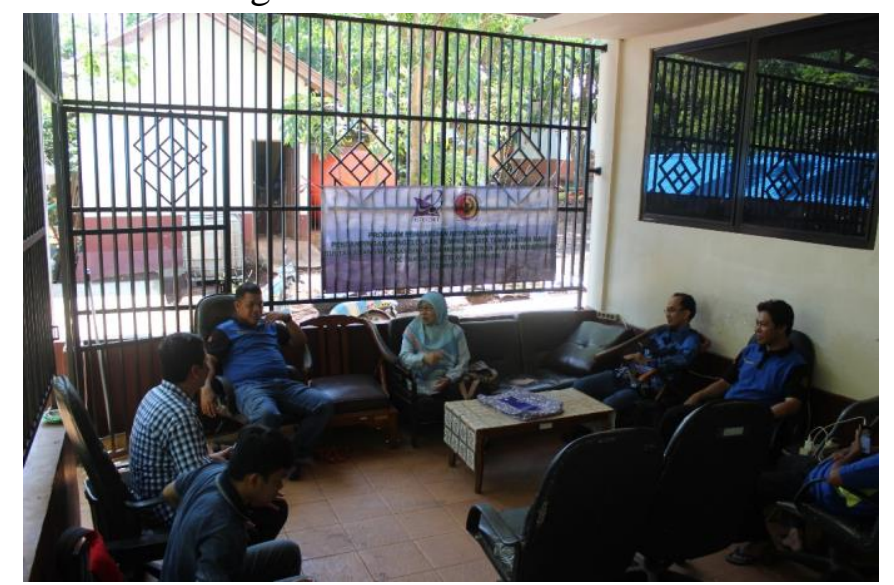

Gambar 2. Pemaparan Program dari Ketua TIM

Kegiatan ini diikuti dua belas peserta dari fihak pengelola Tahura. Gambar 3 Adalah pemaparan materi dari narasumber Arifin Noor Asyikin, ST., MT dan Agus Setiyo Budi Nugroho, ST., M.Kom. 


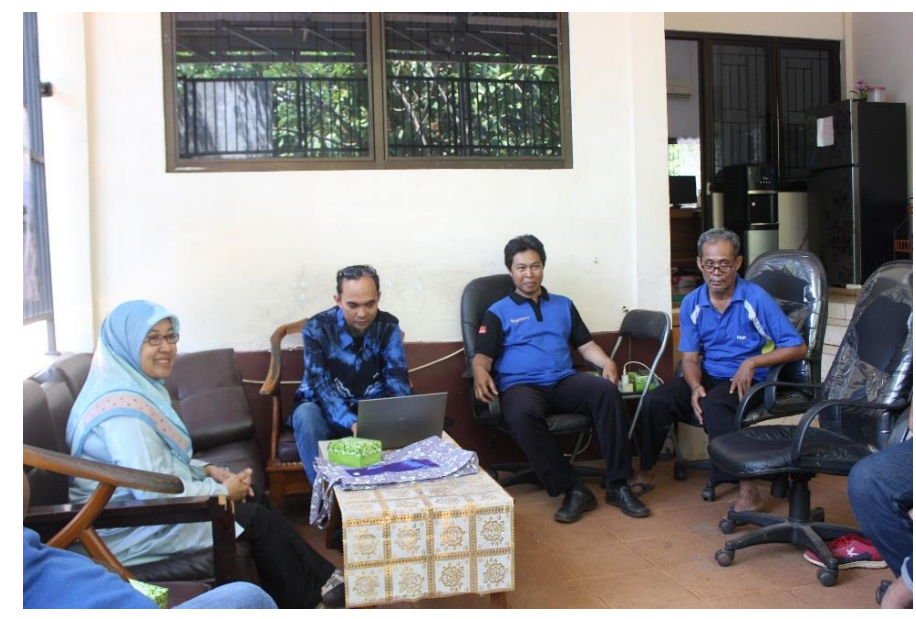

Gambar 3. Pemaparan Materi

Gambar 4, dan gambar 5 adalah permintaan fitur tambahan dari fihak pengelola tahura yaitu adanya pengelolaan lahan kemah secara terkomputerisasi.

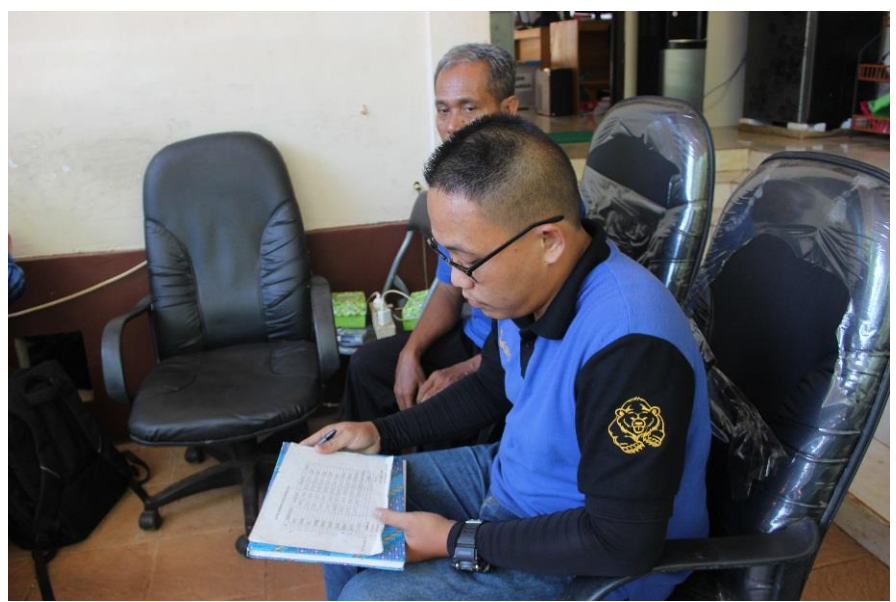

Gambar 4. Penambahan Fitur pengelolaan Lahan kemah

Gambar 5 adalah gambar tim pengabdian dari program studi teknik informatika jurusan teknik elektro 


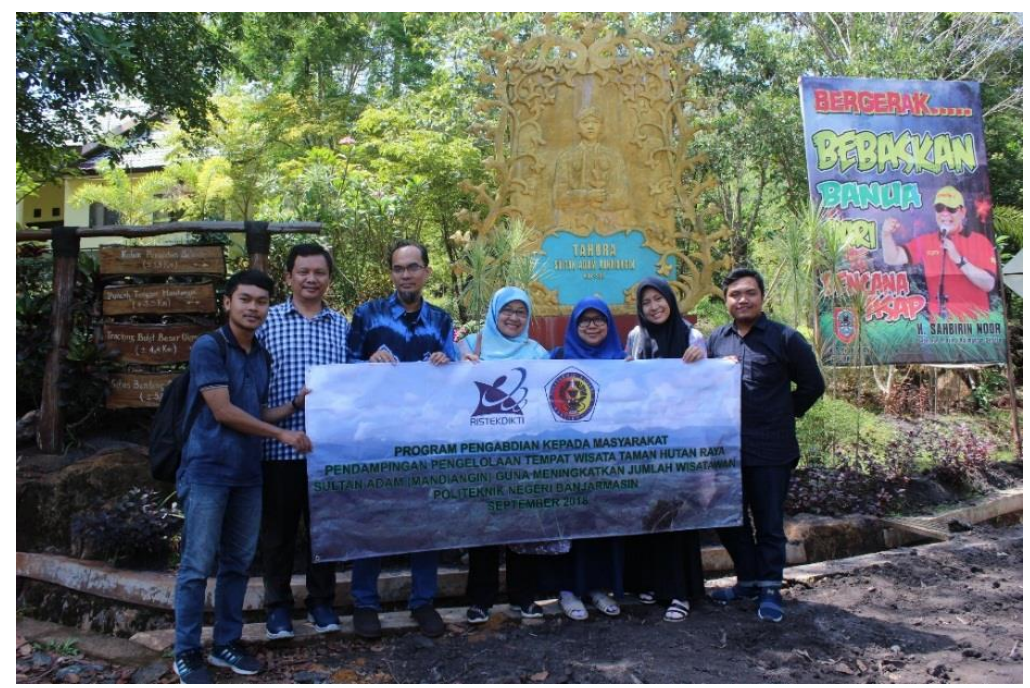

Gambar 5. Foto Bersama TIM PPM dengan Teknisi dan Mahasiswa

Gambar 6 adalah foto bersama tim PPM bersama dengan pengelola tahura, akan tetapi tidak seluruh pengolal dapat mengikuti kegiatan foto bersama dikarenakan harus bertugas meninjau hutan.

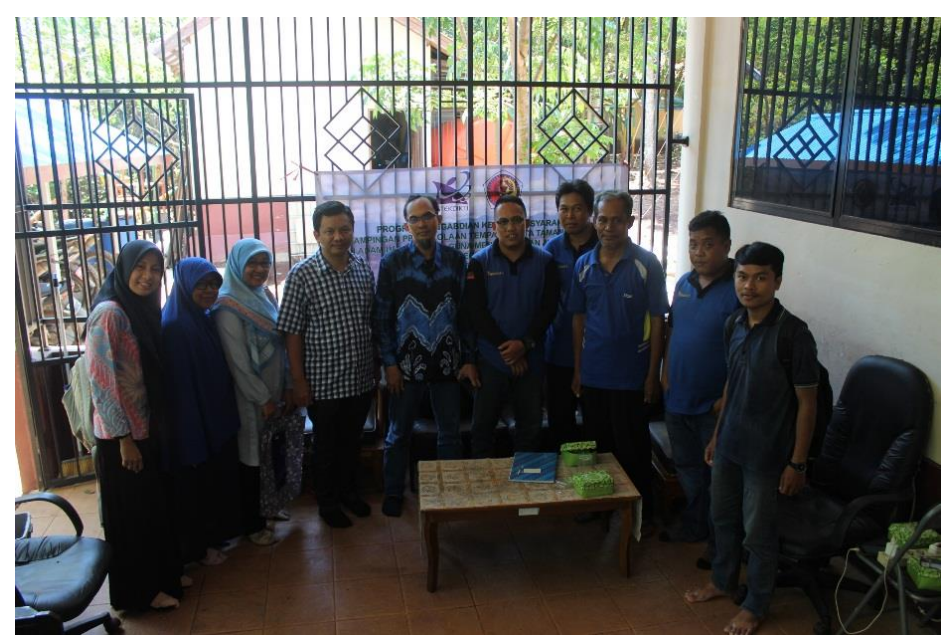

Gambar 6. Foto Bersama Pengelola Tahura

Gambar 7 adalah kegiatan pengambilan foto udara lokasi wisata Tahura Mandiangin yang selanjutnya akan diupload di web tahura. 


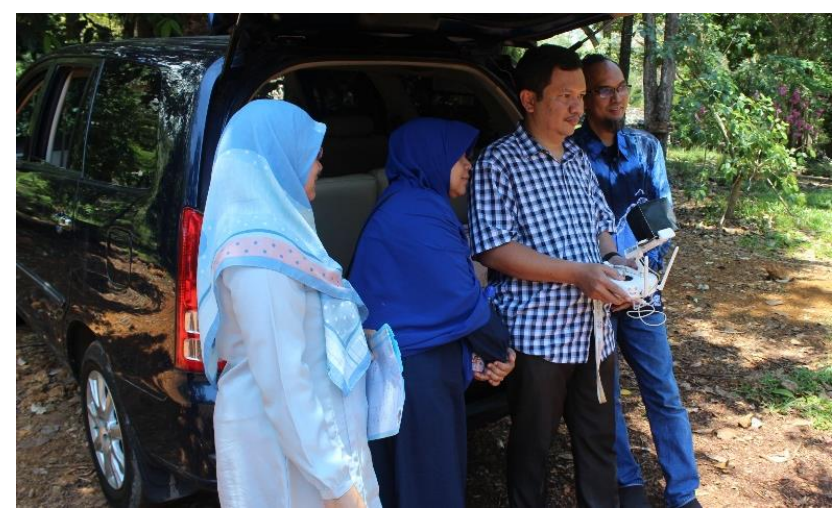

Gambar 7. Pengambilan, foto Tahura menggunakan drone

\section{Website Taman Hutan Rakyat Mandiangin}

Website tahura dapat di akses di alamat http://tahura.provkalsel.id/ Tampilan umum merupakan tampilan yang dapat dilihat semua orang.

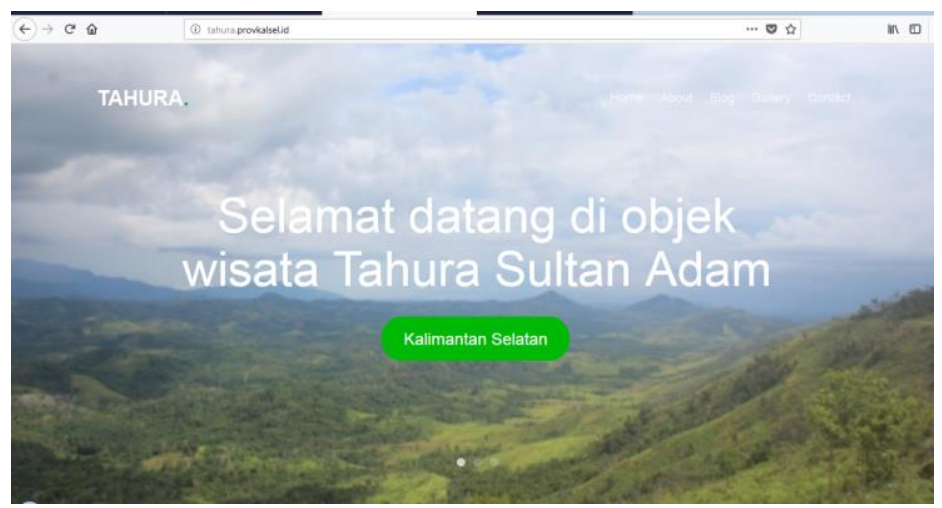

Gambar 8. Tampilan Awal Website

Gambar 8 merupakan tampilan awal website objek wisata Tahura. Tampilan awal ini memiliki lima menu yaitu, home, about, gallery, contact. Menu home berisi informasi tentang objek wisata Tahura yang dijadikan hutan pendidikan ULM (Universitas Lambung Mangkurat), situs sejarah Benteng Belanda, wisata air terjun, kawasan berkemah, serta artikel terbaru terkait dengan objek wisata Tahura. Menu about berisi informasi Tahura lebih detail baik itu ukuran, lokasi, tiket masuk, serta fasilitas pendukung yang ada pada pada objek wisata. Menu gallery berisi koleksi foto keindahan objek wisata Tahura.Serta menu contact yang berisi alamat, nomer telpon, serta email pengelola Tahura. Pada bagian menu ini juga tersedia form mengirim pesan atau chat offline dengan pengelola, hal ini bertujuan untuk mempermudah apabila pengunjung web mengajukan pertanyaan dengan pihak pengelola.

Untuk masuk sebagai admin, harus login terlebih dahulu seperti yang ditunjukkan pada gambar 9 


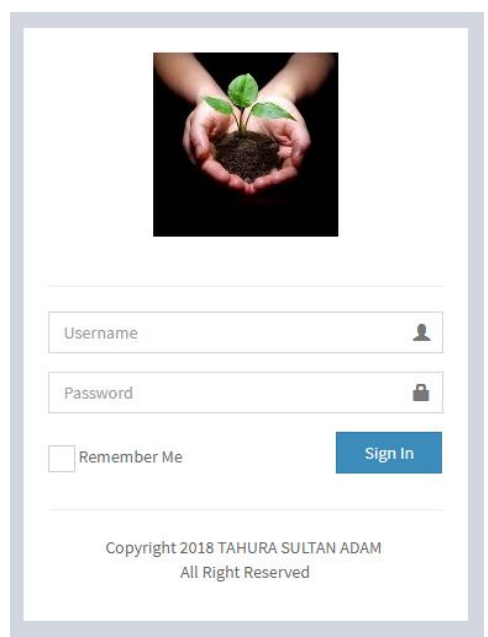

Gambar 9. Tampilan Login sebagai admin

Setelah login sebagai admin, maka tampil dashboard. Yang mana pada dashboard, admin dapat melihat jumlah pengunjung website serta dapat dilihat aplikasi apa yang digunakan pengunjung untuk mengakses website Tahura untuk memperjelas uraian di atas dapat dilihat pada gambar 10 .

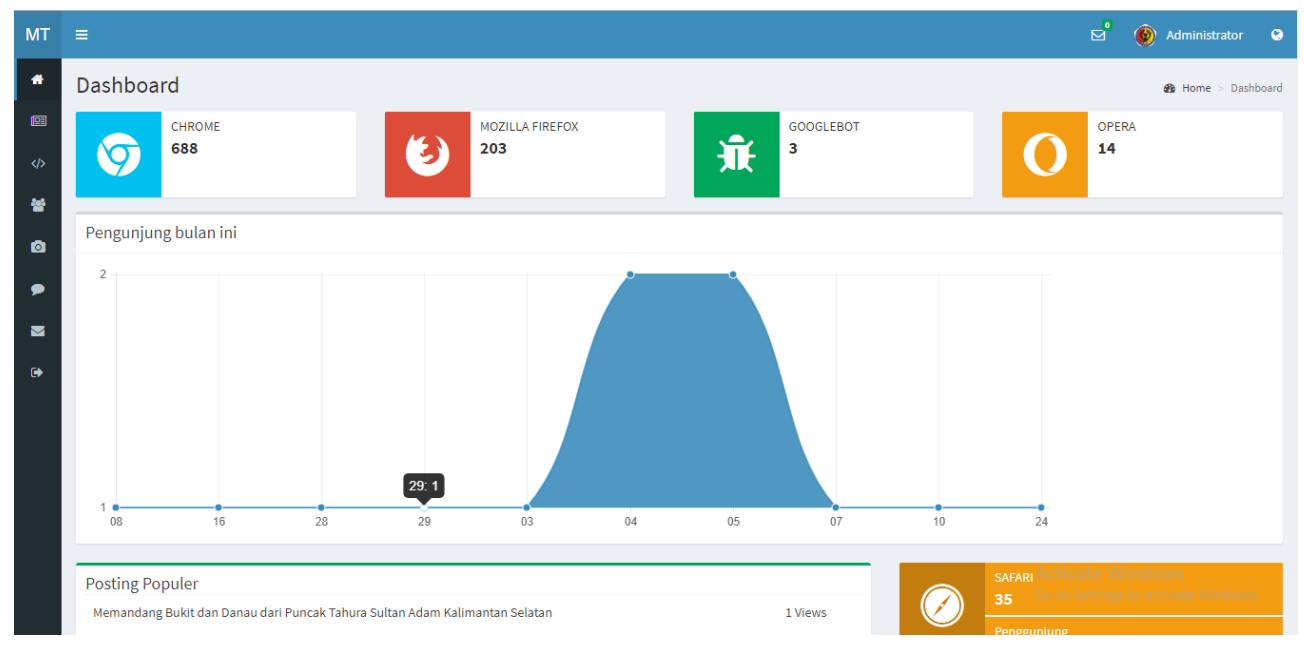

Gambar 10. Tampilan dashboard admin 


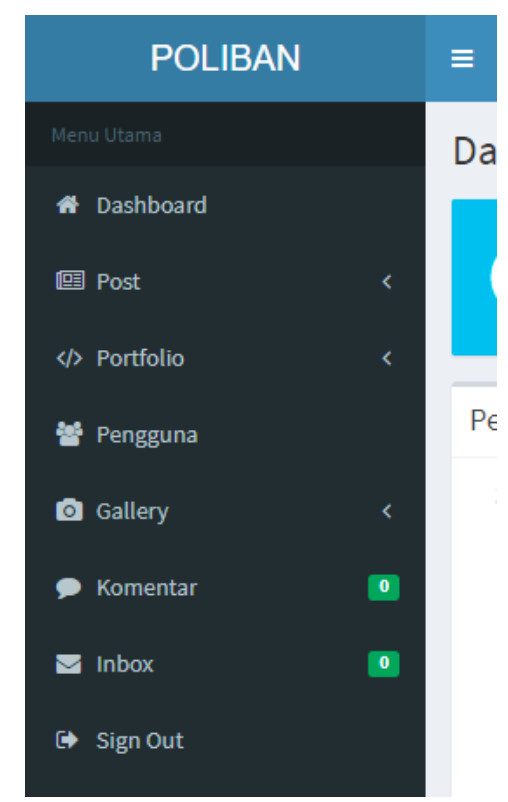

Gambar 11. Sidebar website Tahura

Gambar 11 merupakan tampilan sidebar tampilan admin. Pada bagian sidebar admin dapat mengelola website dengan beberapa menu yang tersedia pada sidebar yaitu, post dan portofolio. Pengelola dapat menambahkan artikel terbaru pada poftofolio. Gallery dapat digunakan admin untuk mengunggah foto objek wisata Tahura. Menu komentar menampilkan komentar yang ditulis pengunjung pada foto ataupun artikel. Menu inbox yang berisi pesan yang dikirm pengunjung pada menu contact.

\section{KESIMPULAN}

Berdasarkan kegiatan pengabdian kepada masyarakat yang telah dilaksanakan di kantor pengelola taman hutan rakyat (tahura) Mandiangin, maka kesimpulan yang dapat paparkan adalah bahwa kegiatan telah berjalan dengan lancar dan mendapatkan antusias yang positif dari staf pengelola Tahura Mandiangin.

Pengelola dapat menggunakan website untuk mengelola informasi terkait beragam kegiatan yang dilaksanakan serta dapat mengelola penyewaan lahan kemah yang biasanya digunakan oleh warga.

\section{UCAPAN TERIMA KASIH}

Atas terlaksananya kegiatan pengabdian kepada masyarakat ini kami mengucapkan terima kasih kepada pengelola objek wisata taman hutan rakyat (tahura) mandiangin dan Politeknik negeri Banjarmasin melalui dana DIPA 2018 yang telah mendanai kegiatan ini.

\section{DAFTAR PUSTAKA}


Ch. Wolah, F. F. (2016). Peranan Promosi Dalam Meningkatkan Kunjungan Wisatawan Di Kabupaten Poso. e-journal "Acta Diurna” Volume V. No.2.

Jannah, N. F., Sugandi, \& Althalets, F. (2018). Strategi Media Promosi Dalam Meningkatkan Kunjungan Daya Tarik Wisata Rumah Ulin Arya. eJournal llmu Komunikasi, 2018, 6 (1), 428-440.

bappelitbangkabbanjar. (2016). Diambil kembali dari bappelitbang.banjarkab.go.id:

http://bappelitbang.banjarkab.go.id/wisata/destinasi/informasi/2 